\title{
Polycomb Proteins in Hematopoiesis and Hematologic Malignancie
}

\section{Jie Li*}

\section{Department of Pathology, Laura and Isaac Perlmutter Cancer Center, New York University School of Medicine, USA}

*Corresponding author: Jie Li, Department of Pathology, Laura and Isaac Perlmutter Cancer Center, New York University School of Medicine, New York, USA, E-mail: Jie.Li@nyumc.org

\begin{abstract}
In recent years, the Polycomb group (PcG) of proteins has been revealed to be involved in the regulation of hematologic stem cell function and differentiation and have been broadly linked to hematologic malignancies. Polycomb proteins are histone modifiers that contain two multi-protein complexes: Polycomb Repressive Complex 1 and 2 (PRC1 and PRC2). As each PcG gene present multiple orthologs, distinct PRC1 and PRC2 sub-complexes exist in different differentiation stage and tissues. Aberrant expression or mutation of individual PcG gene is likely to result in alteration of the PRC composition that is crucial for its enzymatic activity and target selectivity. Considering the dramatically increasing data on the regulation and functions of polycomb proteins, this review focuses on hematopoiesis and hematologic malignancies.
\end{abstract}

\section{Keywords}

Epigenetic, Polycomb proteins, Hematopoiesis, Hematologic malignancies

\section{Introduction}

The hematopoietic system is a well-established model for the homeostatic mechanism between self-renewal and differentiation. One Hematopoietic stem cell (HSC) could asymmetrically divide to a HSC destined for maintaining its line and to a multipotent progenitor, which could undergo expansion and generate large numbers of lineage-committed progenitors to consistently generate abundant numbers of new blood cells through the differentiation during our entire lifespan. In concept, one HSC is sufficient to generate the entire hematopoietic system.

Aberrant regulation of the differentiation of HSC could give rise to immortalized progenitors that lost proliferation control, leading to the development of hematologic malignancies, including leukemia, lymphoma, and multiple myeloma. Hematologic malignancies are originated from blood-forming tissue, such as the bone marrow, or in the cells of the immune system.

Although hematopoiesis and hematologic malignancies are regulated by multiple lineage-specific transcriptional factors [1], cancer genomic sequencing data from patients revealed that the frequency of genetic aberrations in hematologic cancer is much lower than most other malignancies, suggesting that epigenetic mechanisms are critical for hematologic malignancies [2,3]. Reciprocally, epigenetic modifiers that are aberrantly regulated in hematologic malignancies play a prominent role on hematopoiesis, including both self-renewal and differentiation of hematopoietic stem cells. One of the major epigenetic regulators is the class of polycomb-group ( $\mathrm{PcG}$ ) proteins that repress numerous genes involved in various biological process, such as cell differentiation, and cell cycle processes [4].

\section{Polycomb Group (Pcg) Proteins}

Polycomb group (PcG) proteins were first reported as an essential complex for controlling segmentation in drosophila [5]. In Drosophila, most of PcG target genes present specific cis-regulatory sequences named Polycomb-repressed elements (PREs) [6]. In mammals, PcG proteins incorporate two major functional complexes named polycomb repressive complex (PRC) 1 and 2 [3]. The canonical PRC1 complex consists of four core subunits sorted into four gene families including the CBX, PHC, PCGF and RING1. Each of these four core subunits presents multiple orthologs, which incorporate dynamic patterns of PRC1 complex depend on the differentiated status [7]. Through the ubiquitin E3 activity of its RING1 subunit, PRC1 mediates transcriptional repression by promoting the monoubiquitination of $\mathrm{H} 2 \mathrm{~A}$ at lysine 119 [8]. The PRC2 complex comprises three core sub-

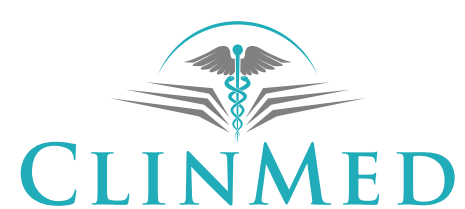

INTERNATIONAL LIBRARY
Citation: Li J (2017) Polycomb Proteins in Hematopoiesis and Hematologic Malignancie. Int J Blood Res Disord 4:025. doi.org/10.23937/2469-5696/1410025

Received: September 17, 2016: Accepted: March 17, 2017: Published: March 20, 2017

Copyright: (C) 2017 Li J. This is an open-access article distributed under the terms of the Creative Commons Attribution License, which permits unrestricted use, distribution, and reproduction in any medium, provided the original author and source are credited. 


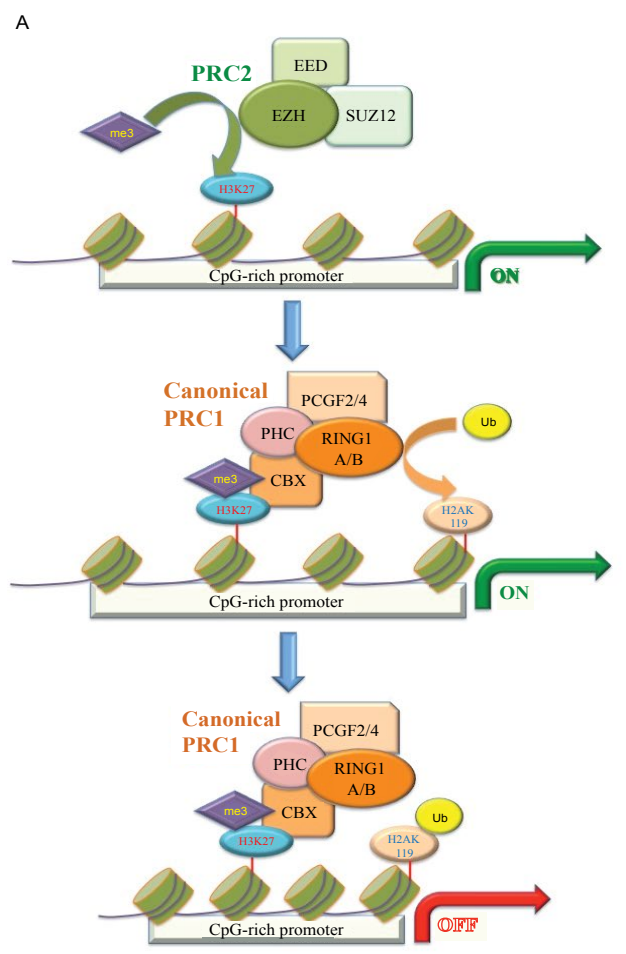

B

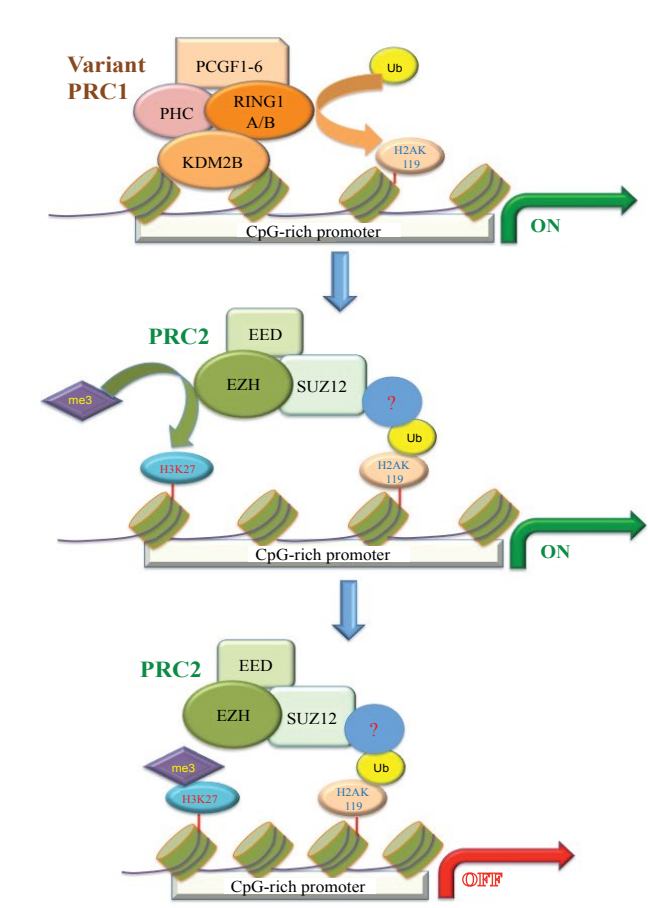

Figure 1: PRC1 and PRC2 can be recruited to chromatin in two different models. A) The "PRC2-dependent" model is based on the initial literature and implies that PRC2 mediates canonical PRC1 recruitment via H3K27me3 recognition. This scheme introduces the existence of PRC2-independent PRC1 sub-complexes that bind the same genomic loci independently of H3K27me3 and play a major contribution to sustain H2Aubq levels; B) The "PRC1-dependent" model shows that PRC2 can be directly recruited to chromatin by variant PRC1 sub-complexes, potentially by recognizing H2AK119 mono-ubiquitination. The subunit KDM2B in variant PRC1 directly binds to CpG-rich DNA.

units: suppressor of zeste 12 homolog (SUZ12), embryonic ectoderm development (EED) and one of two Enhancer of Zeste orthologs (EZH), EZH1 or EZH2 [9]. Through the histone methyltransferase activity of EZH2 or EZH1, PRC2 promotes the tri-methylation of $\mathrm{H} 3$ at lysine 27 (H3K27me3) generally associated with transcriptional repressive gene loci $[10,11]$. Intriguingly, both EZH1 and EZH2 have been revealed as transcriptional co-activators, suggesting that non-PRC2 function of EZHs may play an important role on RNA polymerase II elongation and drug-resistant of prostate cancer cells [12,13]. PRC2-mediated H3K27me3 is specifically recognized and bound by the chromo-domain of $C B X$ subunit, thus recruiting PRC1 complex, which place PRC2 in the upstream of PRC1 (Figure 1A). RYBP is also known as RING1 And YY1-Binding Protein. It plays a role on the formation of non-canonical PRC1 complexes, which mediate H2A ubiquitination at polycomb target sites independent on PRC2 and H3K27me3 $[14,15]$. In addition, the RUNX1/CBF $\beta$ transcription factor complex mediates site-specific PRC1 chromatin recruitment also through PRC2-independent manner [16]. Intriguingly, it has been reported that PRC1-dependent H2AK119ub1 leads to recruitment of PRC2 and H3K27me3 to effectively initiate a polycomb domain [17], which place PRC1 into the upstream of PRC2 (Figure 1B). As various mechanisms have been found for recruitment of PRC1 and PRC2 in different cell types, the interdependence between PRC1 and PRC2 association at target gene loci is still an important issue to be addressed [18].

\section{Polycomb Proteins in Hematopoiesis}

BMI-1 is crucial for the maintenance of self-renewal of hematopoietic stem cell (HSCs) [19]. The number of HSCs was markedly reduced in postnatal Bmi-1-/- mice and the self-renewal of adult HSCs was no detectable, indicating a cell autonomous defect in Bmi-1-/- mice [20]. Consistent to this phenotype, the expression of the genes associated with stem cell, cell survival and proliferation including $\mathrm{p} 16$ Ink4a and p19Arf was altered in bone marrow cells of the Bmi-1-/- mice. Intriguingly, Bmi-1 directly targets the Cdkn2a locus, which encodes P16 ${ }^{\text {Ink4a }} /$ P19 Arf [21]. Double knockout of Bmi-1 and Cdk$n 2 a$ revealed a partial rescue of HSC function, suggests that the repression of cell cycle inhibitor P16 ${ }^{\operatorname{lnk4a}} / \mathrm{P} 19^{\text {Arf }}$ by Bmi-1 is critical in HSCs [21]. Cells derived from Bmi1-/- mice also have impaired mitochondrial function resulting in a dramatically increase of reactive oxygen species and subsequent induce the DNA damage response mediated cell death, indicating that Bmi-1 may have a protective effect against oxidative stress that plays a crucial role in the self-renewal and survival capacity of HSCs [22]. In addition, loss of Bmi-1 lead to premature expression of B-lymphoid genes in progenitors accompanied by accelerated lymphoid lineage specification, indicating that Bmi-1 is a possible inhibitory factor of lymphoid lineage differentiation [23]. In contrast to Bmi-1, knockout of Mel-18, another PCGF gene family member, failed to cause apparent defect in the self-re- 
newal of HSCs but increased proliferation of B-cells, suggesting that Mel-18 plays a role for in more differentiated cells [24]. Polycomb chromobox (CBX) family members show distinct expression patterns dependent on HSC-stage-specific, indicating various formations of PRC1 complexes present during HSC differentiation [25]. Transplanted CBX2-overexpressing HSCs in mice showed only B-cell reconstitution, suggesting that CBX2 is involved in lymphopoiesis, but not myelopoiesis [25]. $\mathrm{CBX7}$ is highly expressed in the HSCs and plays an irreplaceable role in the self-renewal of HSCs by repressing the expression of progenitor-specific genes, suggesting that the PRC1 complex in HSCs preferentially contains CBX7 [25]. In contrast to CBX7, over expression of $\mathrm{CBX} 2, \mathrm{CBX} 4$ or $\mathrm{CBX} 8$ promotes the differentiation and exhaustion of HSCs, suggesting that other $C B X$ proteins can compete with $\mathrm{CBX7}$ to incorporate $\mathrm{CBX2-}$, $\mathrm{CBX} 4$ - or $\mathrm{CBX} 8$-containing PRC1 complexes that target the genes associated with the differentiation of HSCs [25]. On the other hand, the role of non-CBX containing PRC1 complexes in hematopoiesis is much less known. Recently, PCGF1 mediated transcriptional repression of Hox genes has been revealed to be required for the self-renewal in Runx1-/- HSCs, suggesting cooperation of transcriptional and epigenetic regulation is crucial for hematopoietic differentiation [26].

Comparing to PRC1, the role of PRC2 in hematopoiesis is mainly dependent on the EZHs proteins. Comparing to the ubiquitously expression of EZH2, EZH1 is a backup gene that is highly expressed in adult HSC but not in fetal HSC. Whereas EZH2-/- embryos died of anemia due to insufficient expansion of HSCs/progenitor cells and erythropoiesis, deletion of EZH2-/- in adult bone marrow had no alteration on hematopoiesis, suggesting that EZH1 complements EZH2 in the BM, but not in the fetal liver [27]. Deletion of Eed, a core subunit for the formation of both EZH1- and EZH2- containing PRC2 complexes, results in de- pletion of adult bone marrow HSCs while fetal liver HSCs are produced in normal numbers, suggesting that Eed present the EZH-independent function [28]. Although Eed/- neonatal HSCs still expressed HSC signature genes, they were unable to differentiate into mature blood cells and were prone to cell death [28]. Deletion of Cdkn2a, whereas revealed partial rescue of HSC function in Bmi-1-/- mice, enhances hematopoietic stem/progenitor cell (HSPC) survival but fails to restore HSC functions in Eed-null mice [28]. These findings suggested that PRC2 plays a role during hematopoietic differentiation in a different manner with PRC1. Consistent with the role of PRC2 in transcriptional repression, Eed-/- HSCs present depression of PRC2 target genes largely associated with HSC self-renewal, differentiation and apoptosis, indicating that PRC2 suppresses genes of diverse pathways ensuring normal HSC functions [28]. Recently, it has been revealed that EZH1 and EZH2 undergo an expression switch mediated by GATA factors during blood cell development and loss of EZH2 expression results in repositioning of EZH1 chromatin occupancy and transcriptional activity (Figure 2), suggesting that the dynamic composition of PRC2 subunit leads to a switch from canonical repression to non-canonical activation during the differentiation from HSCs to progenitors [29]. More intriguingly, an EZH1-SUZ12 sub-complex lacking EED, named a non-canonical PRC2 complex, was identified to occupy active chromatin domains, and positively regulates gene expression [29]. In addition, EZH2 also plays a critical role in the early stage of $B$ cell development and rearrangement of the immunoglobulin heavy chain gene (Igh) [30].

\section{Polycomb Proteins in Hematopoietic Malignancies}

Bmi-1 has been found to be involved in leukemogenesis since it was recognized as a collaborator of c-Myc in the induction of B-cell lymphomas [31]. BMI-1 is commonly highly expressed in patients with myelodysplastic syndromes (MDS) [32], acute myeloid leukemia (AML) [33], chronic myeloid leukemia (CML) [34] and various

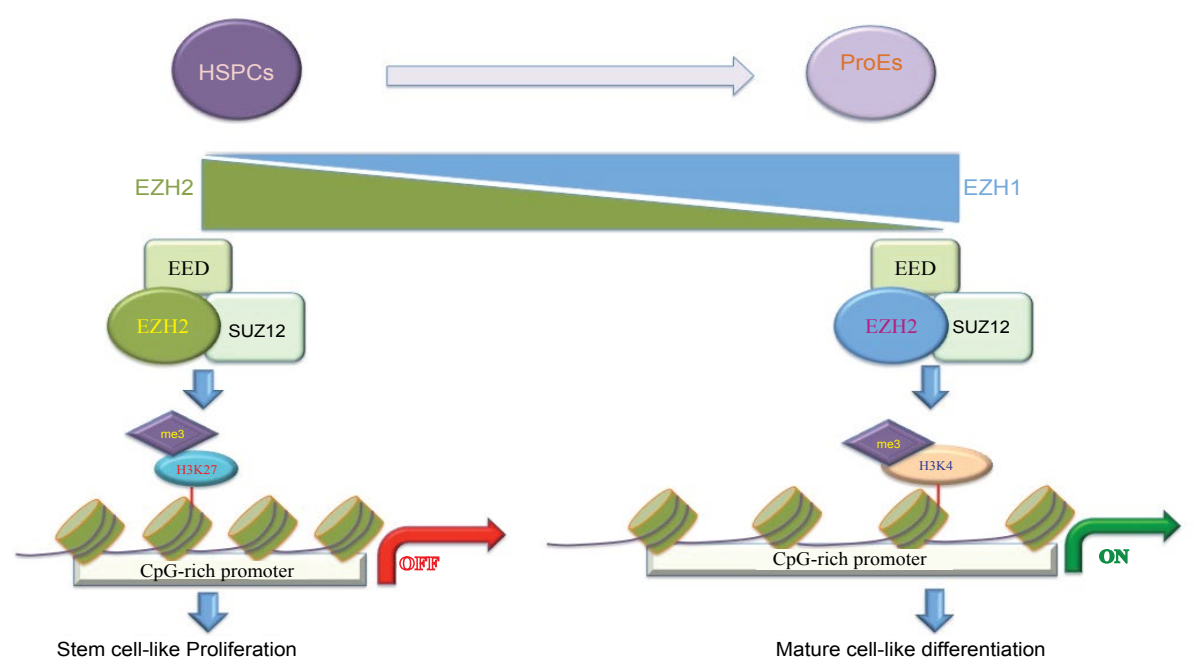

Figure 2: The dynamic PRC2 complexes switch during HSCs differentiation. This cartoon represents a switch from EZH2 to EZH1 expression during he differentiation of hematopoietic stem/ progenitor cells (HSPCs) to highly enriched populations of erythroid progenitor cells (ProEs). In contrast to EZH2, EZH1 forms a non-canonical PRC2 complex and occupies active chromatin to enhance the expression of genes involved in differentiation. 
types of lymphoma [35]. More intriguingly, BMI-1 expression is strongly correlated with disease progression and is associated with a poor prognosis in the patients with AML [33] and CML [36]. Studies in various leukemic mouse models suggested that Bmi-1 might be an important collaborating factor for leukemic transformation mediated by some fusion oncogenes, such as HoxA9-Meis1 [37], MLL-AF9 [38] and BCR-ABL $[39,40]$. In addition, Bmi-1 protects leukemia stem cells (LSCs) from senescence and apoptosis via repressing the expression of p16 and p19 expression [37,41]. Inhibition of BMI-1 expression mediated reactive oxygen species accumulation and apoptosis results in the reduction of proliferative capacity and stem/progenitor cell frequency in AML CD34 positive cells [19]. As BMI-1 could be efficiently inhibited by a small molecule in colon cancer cells in preclinical models [42], its required further studies to test which types of leukemia are susceptible to BMI-1-targeted therapies. Unexpectedly, deletion of Bmi-1 in Cdnkn2a-/- hematopoietic cells induced abnormal megakaryocytopoiesis accompanied by marked extra medullary hematopoiesis, which eventually resulted in lethal myelofibrosis, suggesting that Bmi-1 also present a tumor suppressor function [43]. As Bmi-1 may form different sub-complexes during hematopoietic cells differentiation.

Comparing to for BMI-1, less is known about other PRC1 components. It has been found that aberrant expression of PRC1 genes, such as MEL-18, RING1, HPH1, HPC1, in multiple types of lymphomas $[44,45]$, suggesting that this abnormal formation of PRC1 contributes to the development of hematologic malignancies. Similar to Bmi-1, CBX8 has been shown to be essential in leukemogenesis induced by fusion oncogenes, such as MLL-AF9 [46]. CBX7 is often highly expressed in human follicular lymphomas (FLs) and its over expression in the mouse lymphoid compartment initiates T cell lymphoma and cooperates with c-Myc to induce highly aggressive $B$ cell lymphomas [47]. Although it's remains unclear whether CBX4 is directly involved in leukemia development, it has been found that CBX4 expression is strongly correlated with the angiogenesis [48], metastasis [49] and prognostic [50] of hepatocellular cancer patients. Further studies found that CBX4 increased the transcriptional activity of hypoxia-inducible factor-1 (HIF1) and enhancing the expression of HIF-1 target genes associated cancer metabolism, suggesting that CBX4 might play roles in other types of cancer [51]. RING1A, another PRC1 member, is commonly highly expressed in MDS and AML and is correlated with poor prognosis [32]. Additionally, SNPs in RING1A is correlated with non-Hodgkin lymphoma [52]. Enhanced expression of RING1B, a paralog of RING1A, has detected in multiple types of lymphomas [53].

Inactivating mutations of PRC2 components have been found in multiple types of hematopoietic malignancies. Patients with Early T-cell precursor acute lymphoblastic leukemia (ETP ALL) present high frequencies of mutations in PRC2 core components EZH2, EED and SUZ12 [54,55]. Inactivating somatic mutations of EZH2, EED and SUZ12 also occur frequently in patients with myelodysplastic disorders including myelodysplastic syndromes (MDSs) and MDS/myeloproliferative neoplasm (MPN) overlap disorders (MDS/MPN) [55-57]. In the patients with MDS/MPN, $\mathrm{EZH} 2$ mutations were frequently coincided with tet methylcytosine dioxygenase 2 (TET2) mutations [58]. Whereas deletion of EZH2 alone was enough to induce MDS/MPNlike diseases in mice, double depletion of EZH2 and Tet2 established more advanced myelodysplasia and dramatically accelerated the development of myelodysplastic disorders including both MDS and MDS/MPN [58]. Inactivating mutations of $\mathrm{EZH} 2$ are also frequently associated with RUNX1 mutations in MDS patients and loss of EZH2 significantly promote Runx1 mutant-induced MDS mice model [59]. EZH2-/- mice have been showed the phenotype that is associated with a thymocyte developmental block at the double negative stage and promote the development of T-lineage lymphoblastic leukemia [54]. On the other hand, hyperactive mutations of $\mathrm{EZH} 2$ have been detected in diffuse large B-cell lymphomas [60] and follicular lymphomas [61] in which EZH2 may be a potential therapeutic target $[62,63]$. Overexpression of EZH2 in transgenic mice has been showed to enhance myeloproliferation [64]. Knockdown of PRC2 subunits EED, SUZ12 or EZH1/ EZH2 resulted in proliferation arrest and differentiation in different $A M L$ cell lines [65]. In MLL-rearranged leukemia, genetic mice models revealed that Eed is essential for leukemogenesis and leukemia maintenance, whereas EZH2 is dispensable for MLL-AF9 AML $[66,67]$. In summary, EZH2 plays both roles as pro-oncogene and tumor suppressor depends on different types of hematopoietic malignancies.

\section{Conclusions and Future Perspectives}

PcG proteins have become putative epigenetic regulators in both normal hematopoiesis and various hematological malignancies. The expression of PcG genes is highly regulated during the stage of hematopoietic cell differentiation. Aberrant expression or mutation of PcG genes is associated with different types of hematopoietic malignancies. Intriguingly, individual PcG genes display either tumor suppressor or oncogenic functions largely depending on the cell context. As each PcG gene present multiple orthologs, distinct PRC1 and PRC2 sub-complexes exist in different differentiation stage and tissues. Since distinct polycomb sub-complexes might target specific gene loci with different recruiting mechanisms, it is required more work to address the mechanism of the compositional switch and PRC recruitment. Overall, understanding the molecular mechanism of the genetic alterations and composition switch of polycomb proteins will not only provide important knowledge for hematopoiesis but also be beneficial for developing pharmacological method targeting of PRC compositions for the treatment of hematological malignancies. 


\section{References}

1. Ebina W, Rossi DJ (2015) Transcription factor-mediated reprogramming toward hematopoietic stem cells. EMBO J 34: 694-709.

2. Kandoth C, McLellan MD, Vandin F, Kai Ye, Beifang Niu, et al. (2013) Mutational landscape and significance across 12 major cancer types. Nature 502: 333-339.

3. Haladyna JN, Yamauchi T, Neff T, Bernt KM (2015) Epigenetic modifiers in normal and malignant hematopoiesis. Epigenomics 7: 301-320.

4. Radulovic V, de Haan G, Klauke K (2013) Polycomb-group proteins in hematopoietic stem cell regulation and hematopoietic neoplasms. Leukemia 27: 523-533.

5. Lewis EB (1978) A gene complex controlling segmentation in drosophila. Nature 276: 565-570.

6. Muller J, Kassis JA (2006) Polycomb response elements and targeting of polycomb group proteins in drosophila. Curr Opin Genet Dev 16: 476-484.

7. Kuzmichev A, Margueron R, Vaquero A, Preissner TS, Scher $M$, et al. (2005) Composition and histone substrates of polycomb repressive group complexes change during cellular differentiation. Proc Natl Acad Sci U S A 102: 1859-1864.

8. Cao R, Tsukada Y, Zhang Y (2005) Role of bmi-1 and ring1a in h2a ubiquitylation and hox gene silencing. Mol Cell 20: 845-854.

9. Xu B, Konze KD, Jin J, Wang GG (2015) Targeting ezh2 and prc2 dependence as novel anti-cancer therapy. Exp Hematol 43: 698-712.

10. Cao R, Wang L, Wang $H$, Xia L, Erdjument-Bromage $H$, et al. (2002) Role of histone h3 lysine 27 methylation in polycomb-group silencing. Science 298: 1039-1043.

11. Lund K, Adams PD, Copland M (2014) Ezh2 in normal and malignant hematopoiesis. Leukemia 28: 44-49.

12. Xu K, Wu ZJ, Groner AC, He HH, Cai C (2012) Ezh2 oncogenic activity in castration-resistant prostate cancer cells is polycomb-independent. Science 338: 1465-1469.

13. Mousavi K, Zare H, Wang AH, Sartorelli V (2012) Polycomb protein ezh1 promotes rna polymerase ii elongation. Mol Cell 45: 255-262.

14. Gao Z, Zhang J, Bonasio R, Strino F, Sawai A, et al. (2012) Pcgf homologs, cbx proteins, and rybp define functionally distinct prc1 family complexes. Mol Cell 45: 344-356.

15. Tavares L, Dimitrova E, Oxley D, Webster J, Poot R, et al. (2012) Rybp-prc1 complexes mediate h2a ubiquitylation at polycomb target sites independently of prc2 and h3k27me3. Cell 148: 664-678.

16. Yu M, Mazor T, Huang $H$, Huang $H T$, Kathrein $\mathrm{KL}$, et al. (2012) Direct recruitment of polycomb repressive complex 1 to chromatin by core binding transcription factors. Mol Cell 45: 330-343.

17. Blackledge NP, Farcas AM, Kondo T, King HW, McGouran JF, et al. (2014) Variant prc1 complex-dependent h2a ubiquitylation drives prc2 recruitment and polycomb domain formation. Cell 157: 1445-1459.

18. Scelfo A, Piunti A, Pasini D (2015) The controversial role of the polycomb group proteins in transcription and cancer: How much do we not understand polycomb proteins? FEBS J 282: 1703-1722.

19. Rizo A, Olthof S, Han L, Vellenga E, de Haan G, et al. (2009) Repression of bmi1 in normal and leukemic human cd34(+) cells impairs self-renewal and induces apoptosis. Blood 114: 1498-1505.
20. Park IK, Qian D, Kiel M, Becker MW, Pihalja M, et al. (2003) $\mathrm{Bmi}-1$ is required for maintenance of adult self-renewing haematopoietic stem cells. Nature 423: 302-305.

21. Jacobs JJ, Kieboom K, Marino S, DePinho RA, van Lohuizen $\mathrm{M}$, et al. (1999) The oncogene and polycomb-group gene bmi-1 regulates cell proliferation and senescence through the ink4a locus. Nature 397: 164-168.

22. Liu J, Cao L, Chen J, Song S, Lee IH, et al. (2009) Bmi1 regulates mitochondrial function and the DNA damage response pathway. Nature 459: 387-392.

23. Oguro H, Yuan J, Ichikawa H, Ikawa T, Yamazaki S, et al. (2010) Poised lineage specification in multipotential hematopoietic stem and progenitor cells by the polycomb protein bmi1. Cell Stem Cell 6: 279-286.

24. Tetsu $\mathrm{O}$, Ishihara $H$, Kanno $R$, Kamiyasu $M$, Inoue $H$, et al. (1998) Mel-18 negatively regulates cell cycle progression upon $b$ cell antigen receptor stimulation through a cascade leading to c-myc/cdc25. Immunity 9: 439-448.

25. Klauke K, Radulovic V, Broekhuis M, Weersing E, Zwart E, et al. (2013) Polycomb cbx family members mediate the balance between haematopoietic stem cell self-renewal and differentiation. Nat Cell Biol 15: 353-362.

26. Ross K, Sedello AK, Todd GP, Paszkowski-Rogacz M, Bird AW, et al. (2012) Polycomb group ring finger 1 cooperates with runx 1 in regulating differentiation and self-renewal of hematopoietic cells. Blood 119: 4152-4161.

27. Mochizuki-Kashio M, Mishima Y, Miyagi S, Negishi M, Saraya A, et al. (2011) Dependency on the polycomb gene ezh2 distinguishes fetal from adult hematopoietic stem cells. Blood 118: 6553-6561.

28. Xie H, Xu J, Hsu JH, Nguyen M, Fujiwara Y, et al. (2014) Polycomb repressive complex 2 regulates normal hematopoietic stem cell function in a developmental-stage-specific manner. Cell Stem Cell 14: 68-80.

29. Xu J, Shao Z, Li D, Xie H, Kim W, et al. (2015) Developmental control of polycomb subunit composition by gata factors mediates a switch to non-canonical functions. Mol Cell 57: 304-316.

30. Su IH, Basavaraj A, Krutchinsky AN, Hobert O, Ullrich A, et al. (2003) Ezh2 controls b cell development through histone h3 methylation and igh rearrangement. Nat Immunol 4: 124-131.

31. Martin-Perez D, Piris MA, Sanchez-Beato M (2010) Polycomb proteins in hematologic malignancies. Blood 116: 5465-5475.

32. Xu F, Li X, Wu L, Zhang Q, Yang R, et al. (2011) Overexpression of the ezh2, ring1 and bmi1 genes is common in myelodysplastic syndromes: Relation to adverse epigenetic alteration and poor prognostic scoring. Annals of hematology 90: 643-653.

33. Chowdhury M, Mihara K, Yasunaga S, Ohtaki M, Takihara $Y$, et al. (2007) Expression of polycomb-group (pcg) protein bmi-1 predicts prognosis in patients with acute myeloid leukemia. Leukemia 21: 1116-1122.

34. Yong AS, Stephens N, Weber G, Li Y, Savani BN, et al. (2011) Improved outcome following allogeneic stem cell transplantation in chronic myeloid leukemia is associated with higher expression of bmi-1 and immune responses to bmi-1 protein. Leukemia 25: 629-637.

35. van Kemenade FJ, Raaphorst FM, Blokzijl T, Fieret E, Hamer KM, et al. (2001) Coexpression of bmi-1 and ezh2 polycomb-group proteins is associated with cycling cells and degree of malignancy in b-cell non-hodgkin lymphoma. Blood 97: 3896-3901.

36. Mohty M, Yong AS, Szydlo RM, Apperley JF, Melo JV (2007) The polycomb group bmi1 gene is a molecular marker for 
predicting prognosis of chronic myeloid leukemia. Blood 110: $380-383$.

37. Lessard J, Sauvageau G (2003) Bmi-1 determines the proliferative capacity of normal and leukaemic stem cells. Nature 423: 255-260.

38. Yuan J, Takeuchi M, Negishi M, Oguro $\mathrm{H}$, Ichikawa $\mathrm{H}$, et al. (2011) Bmi1 is essential for leukemic reprogramming of myeloid progenitor cells. Leukemia 25: 1335-1343.

39. Rizo A, Horton SJ, Olthof S, Dontje B, Ausema A, et al. (2010) Bmi1 collaborates with bcr-abl in leukemic transformation of human cd34+ cells. Blood 116: 4621-4630.

40. Sengupta A, Ficker AM, Dunn SK, Madhu M, Cancelas JA, et al. (2012) Bmi1 reprograms $\mathrm{cml}$ b-lymphoid progenitors to become b-all-initiating cells. Blood 119: 494-502.

41. Jacobs JJ, Scheijen B, Voncken JW, Kieboom K, Berns A, et al. (1999) Bmi-1 collaborates with c-myc in tumorigenesis by inhibiting c-myc-induced apoptosis via ink4a/arf. Genes Dev 13: 2678-2690.

42. Kreso A, van Galen P, Pedley NM, Lima-Fernandes E, Frelin C, et al. (2014) Self-renewal as a therapeutic target in human colorectal cancer. Nat Med 20: 29-36.

43. Oguro H, Yuan J, Tanaka S, Miyagi S, Mochizuki-Kashio M, et al. (2012) Lethal myelofibrosis induced by bmi1-deficient hematopoietic cells unveils a tumor suppressor function of the polycomb group genes. J Exp Med 209: 445-454.

44. Dukers DF, van Galen JC, Giroth C, Jansen P, Sewalt RG, et al. (2004) Unique polycomb gene expression pattern in hodgkin's lymphoma and hodgkin's lymphoma-derived cell lines. Am J Pathol 164: 873-881.

45. Raaphorst FM, Vermeer M, Fieret E, Blokzijl T, Dukers D, et al. (2004) Site-specific expression of polycomb-group genes encoding the hpc-hph/prc1 complex in clinically defined primary nodal and cutaneous large b-cell lymphomas. Am J Pathol 164: 533-542.

46. Tan J, Jones M, Koseki H, Nakayama M, Muntean AG, et al. (2011) Cbx8, a polycomb group protein, is essential for mll-af9-induced leukemogenesis. Cancer Cell 20: 563-575.

47. Scott CL, Gil J, Hernando E, Julie Teruya-Feldstein, Masako Narita, et al. (2007) Role of the chromobox protein cbx7 in lymphomagenesis. Proc Natl Acad Sci U S A 104: 5389-5394.

48. Li J, Xu Y, Long XD, Wang W, Jiao HK, et al. (2014) Cbx4 governs hif-1alpha to potentiate angiogenesis of hepatocellular carcinoma by its sumo e3 ligase activity. Cancer Cell 25: 118-131.

49. Mei Z, Jiao H, Wang W, Li J, Chen G, et al. (2014) Polycomb chromobox 4 enhances migration and pulmonary metastasis of hepatocellular carcinoma cell line mhcc971. Sci China Life Sci 57: 610-617.

50. Jiao HK, Xu Y, Li J, Wang W, Mei Z, et al. (2015) Prognostic significance of cbx4 expression and its beneficial effect for transarterial chemoembolization in hepatocellular carcinoma. Cell Death Dis 6: e1689.

51. Li J, Xu Y, Jiao H, Wei Wang, Zhu Mei, et al. (2014) Sumoylation of hypoxia inducible factor-1alpha and its significance in cancer. Science China Life sciences 57: 657-664.

52. Wang SS, Menashe I, Cerhan JR, Wendy Cozen, Richard K Severson, et al. (2011) Variations in chromosomes 9 and $6 \mathrm{p} 21.3$ with risk of non-hodgkin lymphoma. Cancer Epidemiol Biomarkers Prev 20: 42-49.

53. Sanchez-Beato M, Sanchez E, Gonzalez-Carrero J, Morente M, Díez A, et al. (2006) Variability in the expression of polycomb proteins in different normal and tumoral tissues. A pilot study using tissue microarrays. Mod Pathol 19: 684-694.

54. Simon C, Chagraoui J, Krosl J, Gendron P, Wilhelm B, et al. (2012) A key role for ezh2 and associated genes in mouse and human adult t-cell acute leukemia. Genes Dev 26: 651656.

55. Zhang J, Ding L, Holmfeldt L, Wu G, Heatley SL, et al. (2012) The genetic basis of early $t$-cell precursor acute lymphoblastic leukaemia. Nature 481: 157-163.

56. Ueda T, Sanada M, Matsui H, Yamasaki N, Honda ZI, et al. (2012) Eed mutants impair polycomb repressive complex 2 in myelodysplastic syndrome and related neoplasms. Leukemia 26: 2557-2560.

57. Brecqueville M, Rey J, Bertucci F, Coppin E, Finetti P, et al. (2012) Mutation analysis of asxl1, cbl, dnmt3a, idh1, idh2, jak2, mpl, nf1, sf3b1, suz12, and tet2 in myeloproliferative neoplasms. Genes Chromosomes Cancer 51: 743-755.

58. Muto T, Sashida G, Oshima M, Wendt GR, Mochizuki-Kashio $M$, et al. (2013) Concurrent loss of ezh2 and tet2 cooperates in the pathogenesis of myelodysplastic disorders. J Exp Med 210: 2627-2639.

59. Sashida G, Harada H, Matsui H, Oshima M, Yui M, et al. (2014) Ezh2 loss promotes development of myelodysplastic syndrome but attenuates its predisposition to leukaemic transformation. Nat Commun 5: 4177.

60. Sneeringer CJ, Scott MP, Kuntz KW, Knutson SK, Pollock RM, et al. (2010) Coordinated activities of wild-type plus mutant ezh2 drive tumor-associated hypertrimethylation of lysine 27 on histone h3 (h3k27) in human b-cell lymphomas. Proc Natl Acad Sci U S A 107: 20980-20985.

61. Okosun J, Bodor C, Wang J, Araf S, Yang CY, et al. (2014) Integrated genomic analysis identifies recurrent mutations and evolution patterns driving the initiation and progression of follicular lymphoma. Nat Genet 46: 176-181.

62. Yap DB, Chu J, Berg T, Schapira M, Cheng SW, et al. (2011) Somatic mutations at ezh2 y641 act dominantly through a mechanism of selectively altered prc2 catalytic activity, to increase h3k27 trimethylation. Blood 117: 2451-2459.

63. Morin RD, Johnson NA, Severson TM, Mungall AJ, An J, et al. (2010) Somatic mutations altering ezh2 (tyr641) in follicular and diffuse large b-cell lymphomas of germinalcenter origin. Nat Genet 42: 181-185.

64. Herrera-Merchan A, Arranz L, Ligos JM, de Molina A, Dominguez O, et al. (2012) Ectopic expression of the histone methyltransferase ezh2 in haematopoietic stem cells causes myeloproliferative disease. Nat Commun 3: 623.

65. Shi J, Wang E, Zuber J, Rappaport A, Taylor M, et al. (2013) The polycomb complex prc2 supports aberrant self-renewal in a mouse model of mll-af9;nras(g12d) acute myeloid leukemia. Oncogene 32: 930-938.

66. Neff T, Sinha AU, Kluk MJ, Zhu N, Khattab MH, et al. (2012) Polycomb repressive complex 2 is required for mll-af9 leukemia. Proc Natl Acad Sci U S A 109: 5028-5033.

67. Tanaka S, Miyagi S, Sashida G, Chiba T, Yuan J, et al. (2012) Ezh2 augments leukemogenicity by reinforcing differentiation blockage in acute myeloid leukemia. Blood 120: 1107-1117. 